\title{
Optimization of Conversion of High Free Fatty Acid Jatropha curcas Oil to Biodiesel Using Response Surface Methodology
}

\author{
Prerna Goyal, ${ }^{1}$ M. P. Sharma, ${ }^{1}$ and Siddharth Jain ${ }^{2}$ \\ ${ }^{1}$ Biofuel Research Laboratory, Alternate Hydro Energy Centre, Indian Institute of Technology Roorkee, Uttarakhand 247667, India \\ ${ }^{2}$ NUS Environmental Research Institute, National University of Singapore, Singapore 117411
}

Correspondence should be addressed to Prerna Goyal, prernagoyal282@gmail.com

Received 5 October 2012; Accepted 8 November 2012

Academic Editors: T. García and M. Kostoglou

Copyright (C 2012 Prerna Goyal et al. This is an open access article distributed under the Creative Commons Attribution License, which permits unrestricted use, distribution, and reproduction in any medium, provided the original work is properly cited.

\begin{abstract}
A five-level-four-factor central composite design (CCD) with 54 assays was employed to study the effect of catalyst concentration $(\mathrm{NaOH})$, reaction temperature, reaction time, and methanol/oil molar ratio on the methyl esters yield from Jatropha curcas oil (JCO) during its transesterification. Using response surface methodology (RSM), a quadratic polynomial equation was obtained for Jatropha curcas biodiesel (JCB) yield by regression analysis. Verification experiments confirmed the validity of the predicted model. The high free fatty acids (FFAs) $(14.6 \%)$ of JCO could be reduced to $0.34 \%$ by acid-catalyzed esterification and a JCB yield of $98.3 \%$ was obtained with methanol/oil ratio $(11: 1)$ using $\mathrm{NaOH}$ as catalyst $(1 \% \mathrm{w} / \mathrm{w})$ in 110 min time at $55^{\circ} \mathrm{C}$ temperature. The predicted value of JCB yield is found to be in good agreement with the experimental value at the optimum level of input parameters. The properties of the biodiesel, thus, produced conform to the ASTM and IS specifications, making it an ideal alternative fuel for diesel engines. The model can be effectively used in oil industry to maximize the biodiesel yield from given oil.
\end{abstract}

\section{Introduction}

The rapid increase in energy demand and fast depletion of fossil fuel resources has led to the search for alternative energy sources. Biodiesel, a renewable and biodegradable fuel, has generated considerable interest as a substitute to petrodiesel in recent years. Presently, the main focus is being placed to explore the nonedible oil resources like Jatropha, Pongamia, Mahua, and Neem as a potential source for biodiesel. Jatropha curcas L. oil (JCO) has been assigned top priority by the Government of India as feedstock for biodiesel production, and accordingly, Jatropha curcas plantations are cultivated on about 400,000 ha of land under National Biodiesel Mission of the Government of India, and the oil is expected to be available for biodiesel production in the coming years. The oil can be converted to biodiesel using transesterification, but the type of transesterification to be adopted depends on the free fatty acid (FFA) content of the oil. For the conversion of high FFA JCO, two-step acid-base catalyzed method has been-developed [1] which consists of acid-catalyzed pretreatment/esterification step to reduce the FFA to less than $1 \%$ using $\mathrm{H}_{2} \mathrm{SO}_{4}$ as acid catalyst and transesterification of pretreated oil to biodiesel using alkali catalyst. Its basic objective is to maximize the yield of biodiesel and to achieve higher conversion efficiency of biodiesel production. Different oils are found to contain varying amount of FFAs with ageing and the same holds true for JCO which emphasizes the need for optimization of biodiesel production from JCO in order to maximize the JCB yield. The literature revealed that only few papers are available on the use of response surface methodology (RSM) for the optimization of process variables to maximize the biodiesel yield. Boonmee et al. [2] have studied the effect of three process variables, namely, methanol-to-oil molar ratio, catalyst concentration, and reaction time on the methyl esters yield of JCO using a central composite design (CCD) of 20 experiments and achieved $99.87 \%$ biodiesel yield. Similarly, Tiwari et al. [3] have optimized only two variables, namely, methanol quantity and reaction time using RSM based on five-level-two-factor central composite rotatable design (CCRD) of 21 experiments and obtained biodiesel yield of $99 \%$. The effect of catalyst concentration, reaction temperature, reaction time, and methanol-to-oil ratio on the fatty acid methyl ester (FAME) yield of palm oil was 
studied by Chin et al. [4] using CCRD. In all, 30 experiments were conducted and a quadratic polynomial equation was obtained for evaluating biodiesel yield by multiple regression analysis. Biodiesel yield of $72 \%$ was achieved. Jeong and Park [5] further investigated the effect of three variables, namely, reaction temperature, oil-to-methanol molar ratio, and catalyst quantity $(\mathrm{KOH})$ on biodiesel yield from castor oil using CCRD in 20 experimental runs and obtained about $92 \%$ yield. The effect of above the three variables on the biodiesel yield from animal fat (Lard) was studied by Jeong et al. [6], using CCRD in 20 experiments and achieved $97.8 \%$ yield. The study on the effect of four variables, namely, catalyst concentration, reaction temperature, time and methanol/oil ratio on biodiesel yield from high FFA waste rapeseed oil was examined by Yuan et al. [7] using CCD in 30 experimental runs and reported that the catalyst concentration and reaction time were the limiting conditions and obtained $83 \%$ yield. RSM-based CCRD was used to optimize four process variables: methanol/oil molar ratio, catalyst $\left(\mathrm{NaOCH}_{3}\right)$ concentration, reaction temperature, and reaction time to produce rice bran oil methyl ester in 30 experimental assays by Rashid et al. [8], who obtained $83.3 \%$ biodiesel yield. In view of the above, it can be seen that most of the authors have optimized biodiesel yield using three process variables while few concentrated on four variables using the same optimization technique. No work is reported on optimization of biodiesel yield from JCO using four variables. The present paper, therefore, reports the results of the optimization of four process variables, namely, catalyst $(\mathrm{NaOH})$ concentration $(0-2 \% \mathrm{w} / \mathrm{w})$, reaction temperature $\left(35^{\circ}-55^{\circ} \mathrm{C}\right)$, reaction time $(30-180 \mathrm{~min})$, and methanol/oil ratio $(\mathrm{w} / \mathrm{w})(6: 1-12: 1)$ for transesterification of high FFA JCO using RSM-based CCD to maximize the JCB yield with the help of Design Expert 8.0.6 software. A model to predict the response (JCB yield (\%)) was formulated and validated by analysis of variance (ANOVA). A total of 54 experiments were conducted to get the response experimentally. The experimental results were found in good agreement with the predicted response, thereby proving the credibility of the model.

\section{Materials and Methods}

JCO was procured from Jatropha Vikas Sansthan, New Delhi India. All chemicals like $\mathrm{H}_{2} \mathrm{SO}_{4}, \mathrm{KOH}$, methanol, ethanol, $\mathrm{Na}_{2} \mathrm{SO}_{4}$, and $\mathrm{NaOH}$ were of analytical reagent grade and $99 \%$ pure. $\mathrm{NaOH}$ in pellet form was used as a base catalyst.

2.1. Pretreatment of High FFA JCO. Raw JCO was filtered to remove all insoluble impurities followed by heating at $100^{\circ} \mathrm{C}$ for $10 \mathrm{~min}$ to remove all the moisture. JCO had high FFA (14.60\%), far above the 1\% limit suitable for base catalyzed transesterification reaction. FFAs were, therefore, first converted to esters in a pretreatment process developed by the authors in their laboratory for the production of JCB [1]. The reaction was carried out at a temperature of $50^{\circ} \mathrm{C}$ for $125 \mathrm{~min}$ using conc. $\mathrm{H}_{2} \mathrm{SO}_{4}(1.5 \% \mathrm{v} / \mathrm{v})$ as acid catalyst and methanol as a solvent with methanol/oil ratio
TABLE 1: Independent variables and levels used for CCD in transesterification process.

\begin{tabular}{lccccccc}
\hline $\begin{array}{l}\text { Serial } \\
\text { number }\end{array}$ & Variables & Symbols & \multicolumn{5}{c}{ Levels } \\
& & & -1 & -0.5 & 0 & 0.5 & 1 \\
\hline 1 & $\begin{array}{c}\text { Catalyst } \\
\text { concentration } \\
(\% \text { w/w) }\end{array}$ & $A$ & 0 & 0.5 & 1.0 & 1.5 & 2.0 \\
2 & Temperature $\left({ }^{\circ} \mathrm{C}\right)$ & $B$ & 35 & 40 & 45 & 50 & 55 \\
3 & $\begin{array}{c}\text { Time (min) } \\
\text { Methanol-to-oil } \\
\text { ratio (w/w) }\end{array}$ & D & 30 & 67.5 & 105 & 142.5 & 180 \\
\hline & & & & 7.5 & 9 & 10.5 & 12 \\
\hline
\end{tabular}

of $6.5: 1$, and high FFAs were first reduced to $0.34 \%$ through esterification and the resulting reaction mixture was finally subjected to base catalyzed transesterification process for biodiesel production.

2.2. Base Catalyzed Transesterification of JCO. Pretreated JCO was transesterified by using methanol and $\mathrm{NaOH}$ as base catalyst for the production of JCB [1]. The methyl ester layer was separated, washed with water, heated to remove moisture, and dried over anhydrous $\mathrm{Na}_{2} \mathrm{SO}_{4}$. The transesterification of JCO has been optimized using RSM for the maximization of JCB yield which was calculated using the following:

$$
\begin{aligned}
\text { Yield of JCB }(\%)= & \frac{\text { Total weight of methyl esters }}{\text { Total weight of oil in the sample }} \\
& * 100 \% .
\end{aligned}
$$

2.3. Analysis of JCB. The JCB was prepared in the laboratory under the operating conditions optimized by RSM-based CCD. The JCB was analyzed for fatty acid composition using gas chromatograph (Model: Netal). The process is already described by Jain and Sharma [1].

2.4. ${ }^{1} \mathrm{H}$-NMR Spectroscopy of JCB. ${ }^{1} \mathrm{H}-\mathrm{NMR}$ spectrometer (Model: Bruker DRX-600) available at Institute Instrumentation Centre (IIC) operating at $500 \mathrm{MHz}$ and using deuterated chloroform $\left(\mathrm{CDCl}_{3}\right)$ as a solvent was used to analyze the purity of JCB.

2.5. Physiochemical Properties of JCB. The physical and chemical properties of JCB produced under optimum conditions were determined by using standard methods [9].

2.6. Experimental Design Based on RSM. A five-level, fourfactor CCD was applied for carrying out the optimization studies to maximize the JCB yield. Catalyst concentration $(A)(\%)$, reaction temperature $(B)\left({ }^{\circ} \mathrm{C}\right)$, reaction time (min) $(C)$, and methanol-to-oil molar ratio (w/w) (D) were the independent variables selected to optimize the yield of JCB. The coded and uncoded levels of the independent variables are given in Table 1. 
TABLE 2: CCD arrangement and responses for JCB yield.

\begin{tabular}{|c|c|c|c|c|c|c|}
\hline \multirow{2}{*}{ Run } & \multirow{2}{*}{$\begin{array}{c}\text { Parameter } 1 \\
\text { A: catalyst } \\
\text { concentration } \\
(\%)\end{array}$} & \multirow{2}{*}{$\begin{array}{c}\text { Parameter } 2 \\
B: \underset{ }{\left({ }^{\circ} \mathrm{C}\right)}\end{array}$} & \multirow{2}{*}{$\begin{array}{l}\text { Parameter } 3 \\
\text { C: time } \\
\quad(\min )\end{array}$} & \multirow{2}{*}{$\begin{array}{c}\text { Parameter } 4 \\
\begin{array}{l}\text { D: methanol/oil } \\
\text { ratio }\end{array}\end{array}$} & \multirow{2}{*}{$\begin{array}{l}\text { Experimental } \\
\text { response } \\
\text { JCB yield } \\
(\%)\end{array}$} & \multirow{2}{*}{$\begin{array}{l}\text { Predicted response } \\
\qquad \begin{array}{c}\text { JCB yield } \\
(\%)\end{array}\end{array}$} \\
\hline & & & & & & \\
\hline 1 & 1 & 45 & 105 & 9 & 82.6 & 82.84 \\
\hline 2 & 0 & 45 & 105 & 9 & 89.5 & 89.81 \\
\hline 3 & 0.5 & 40 & 67.5 & 10.5 & 78.2 & 80.37 \\
\hline 4 & 1.5 & 40 & 142.5 & 10.5 & 88.6 & 87.84 \\
\hline 5 & 0.5 & 40 & 67.5 & 10.5 & 77.8 & 80.37 \\
\hline 6 & 0.5 & 50 & 67.5 & 7.5 & 87.1 & 86.76 \\
\hline 7 & 1.5 & 50 & 67.5 & 10.5 & 73.9 & 76.50 \\
\hline 8 & 0.5 & 40 & 142.5 & 7.5 & 91 & 89.83 \\
\hline 9 & 1 & 45 & 105 & 9 & 82.9 & 82.84 \\
\hline 10 & 0.5 & 40 & 67.5 & 7.5 & 86.1 & 87.33 \\
\hline 11 & 1 & 45 & 105 & 9 & 83.1 & 82.84 \\
\hline 12 & 1 & 45 & 105 & 12 & 85.5 & 84.97 \\
\hline 13 & 1 & 45 & 105 & 9 & 82.1 & 82.84 \\
\hline 14 & 1 & 45 & 180 & 9 & 93.4 & 92.65 \\
\hline 15 & 0.5 & 50 & 142.5 & 10.5 & 97.8 & 99.99 \\
\hline 16 & 1 & 45 & 30 & 9 & 78.2 & 79.56 \\
\hline 17 & 1.5 & 50 & 142.5 & 10.5 & 88.3 & 87.10 \\
\hline 18 & 0.5 & 50 & 67.5 & 10.5 & 90 & 87.17 \\
\hline 19 & 0.5 & 40 & 142.5 & 10.5 & 91.8 & 91.86 \\
\hline 20 & 1.5 & 40 & 67.5 & 7.5 & 85.7 & 84.18 \\
\hline 21 & 0.5 & 50 & 142.5 & 7.5 & 90 & 90.98 \\
\hline 22 & 1 & 35 & 105 & 9 & 92.4 & 91.00 \\
\hline 23 & 1.5 & 40 & 142.5 & 7.5 & 81.6 & 84.05 \\
\hline 24 & 1.5 & 40 & 142.5 & 10.5 & 83.8 & 87.84 \\
\hline 25 & 1 & 45 & 105 & 12 & 85.9 & 84.97 \\
\hline 26 & 0.5 & 50 & 67.5 & 10.5 & 90.4 & 87.17 \\
\hline 27 & 1.5 & 40 & 67.5 & 10.5 & 80 & 78.97 \\
\hline 28 & 2 & 45 & 105 & 9 & 73 & 73.37 \\
\hline 29 & 1 & 55 & 105 & 9 & 88.2 & 89.69 \\
\hline 30 & 1.5 & 50 & 142.5 & 7.5 & 77 & 75.94 \\
\hline 31 & 1.5 & 40 & 67.5 & 7.5 & 85.2 & 84.18 \\
\hline 32 & 1 & 45 & 105 & 9 & 82.4 & 82.84 \\
\hline 33 & 1 & 55 & 105 & 9 & 87.9 & 89.69 \\
\hline 34 & 1.5 & 50 & 67.5 & 10.5 & 74.1 & 76.50 \\
\hline 35 & 1.5 & 50 & 67.5 & 7.5 & 74.8 & 74.34 \\
\hline 36 & 1.5 & 50 & 142.5 & 7.5 & 77.3 & 75.94 \\
\hline 37 & 1.5 & 40 & 67.5 & 10.5 & 80.2 & 78.97 \\
\hline 38 & 1 & 45 & 105 & 9 & 82.8 & 82.84 \\
\hline 39 & 0.5 & 50 & 67.5 & 7.5 & 87.5 & 86.76 \\
\hline 40 & 2 & 45 & 105 & 9 & 73.2 & 73.37 \\
\hline 41 & 1 & 45 & 105 & 6 & 79.5 & 80.76 \\
\hline 42 & 1.5 & 50 & 67.5 & 7.5 & 74.5 & 74.34 \\
\hline 43 & 0 & 45 & 105 & 9 & 89.9 & 89.81 \\
\hline 44 & 1.5 & 40 & 142.5 & 7.5 & 81.2 & 84.05 \\
\hline
\end{tabular}


TABle 2: Continued.

\begin{tabular}{|c|c|c|c|c|c|c|}
\hline \multirow{2}{*}{ Run } & Parameter 1 & Parameter 2 & Parameter 3 & Parameter 4 & $\begin{array}{l}\text { Experimental } \\
\text { response }\end{array}$ & Predicted response \\
\hline & $\begin{array}{c}A: \text { catalyst } \\
\text { concentration } \\
(\%)\end{array}$ & $\begin{array}{c}B: \text { temperature } \\
\left({ }^{\circ} \mathrm{C}\right)\end{array}$ & $\begin{array}{l}C: \text { time } \\
(\min )\end{array}$ & $\begin{array}{l}D: \text { methanol/oil } \\
\text { ratio }\end{array}$ & $\begin{array}{l}\text { JCB yield } \\
(\%)\end{array}$ & $\begin{array}{l}\text { JCB yield } \\
(\%)\end{array}$ \\
\hline 45 & 0.5 & 50 & 142.5 & 7.5 & 90.4 & 90.98 \\
\hline 46 & 0.5 & 50 & 142.5 & 10.5 & 98.2 & 99.98 \\
\hline 47 & 1 & 35 & 105 & 9 & 92.1 & 91.00 \\
\hline 48 & 1 & 45 & 105 & 6 & 79.8 & 80.76 \\
\hline 49 & 0.5 & 40 & 67.5 & 7.5 & 86.5 & 87.33 \\
\hline 50 & 0.5 & 40 & 142.5 & 10.5 & 92.1 & 91.86 \\
\hline 51 & 1 & 45 & 30 & 9 & 78.5 & 79.56 \\
\hline 52 & 0.5 & 40 & 142.5 & 7.5 & 91.4 & 89.83 \\
\hline 53 & 1.5 & 50 & 142.5 & 10.5 & 88.7 & 87.10 \\
\hline 54 & 1 & 45 & 180 & 9 & 93.7 & 92.65 \\
\hline
\end{tabular}

TABLE 3: ANOVA for response surface quadratic model.

\begin{tabular}{|c|c|c|c|c|c|}
\hline Source & Sum of squares & Degree of freedom (df) & Mean square & $F$ value & $P$ value prob $>F$ \\
\hline Model & 2078.70 & 14 & 148.48 & 47.43 & $<0.0001$ \\
\hline A: catalyst concentration & 815.10 & 1 & 815.10 & 260.35 & $<0.0001$ \\
\hline$B:$ temperature & 6.75 & 1 & 6.75 & 2.16 & 0.1500 \\
\hline$C:$ time & 520.08 & 1 & 520.08 & 166.12 & $<0.0001$ \\
\hline$D:$ methanol/oil molar ratio & 53.76 & 1 & 53.76 & 17.17 & 0.0002 \\
\hline$A B$ & 172.05 & 1 & 172.05 & 54.95 & $<0.0001$ \\
\hline$A C$ & 13.78 & 1 & 13.78 & 4.40 & 0.0424 \\
\hline$A D$ & 6.13 & 1 & 6.13 & 1.96 & 0.1698 \\
\hline$B C$ & 5.78 & 1 & 5.78 & 1.85 & 0.1820 \\
\hline$B D$ & 108.78 & 1 & 108.78 & 34.75 & $<0.0001$ \\
\hline$C D$ & 162.90 & 1 & 162.90 & 52.03 & $<0.0001$ \\
\hline$A^{2}$ & 4.19 & 1 & 4.19 & 1.34 & 0.2541 \\
\hline$B^{2}$ & 149.83 & 1 & 149.83 & 47.86 & $<0.0001$ \\
\hline$C^{2}$ & 28.97 & 1 & 28.97 & 9.25 & 0.0042 \\
\hline$D^{2}$ & 0.0001157 & 1 & 0.0001157 & 0.00003697 & 0.9848 \\
\hline Residual & 122.10 & 39 & 3.13 & & \\
\hline
\end{tabular}

CV: $2.09 \%, R_{\text {model }}^{2}: 0.945, R_{\text {Adj. }}^{2}: 0.923$, and predicted $R_{\text {model }}^{2}: 0.890$.

2.7. Statistical Analysis. The Design Expert 8.0.6 software was used for the regression and graphical analysis of the data. The maximum values of JCB yield were taken as the response of the design experiment. The experimental data obtained by the above procedure was analyzed by the response surface regression using the following second-order polynomial:

$$
y=\beta_{o}+\sum_{i=1}^{k} \beta_{i} x_{i}+\sum_{i=1}^{k} \beta_{i i} x_{i}^{2}+\sum_{i_{i>j}}^{k} \sum_{j}^{k} \beta_{i j} x_{i} x_{j},
$$

where $y$ is the response (JCB \%), $i$ and $j$ are the linear and quadratic coefficients, respectively, $\beta_{o}$ is the regression co-efficient, and $k$ is the number of factors studied and optimized in the experiment. Statistical analysis of the model was carried out to evaluate the ANOVA. Confirmatory experiments were also carried out to validate the equation.

\section{Results and Discussions}

A total of 54 experiments were performed to get the experimental values of JCB yield. Experimental and predicted values for JCB yield responses at the design points and all the four variables in uncoded form are given in Table 2. The summary of ANOVA is provided in Table 3. The associated probability $(P)$ value for the model is lower than 0.05 (i.e., $\alpha=0.05$ or $95 \%$ confidence) implying the significance of the model. The value of regression coefficient $R^{2}$ for the model is 0.945 , indicating the good fitness of the model. A high value of predicted $R^{2}(0.890)$ is an indication of precision 
TABLE 4: Optimized input process parameters and optimum value of JCB yield.

\begin{tabular}{|c|c|c|c|c|c|c|c|c|c|c|c|}
\hline \multirow{3}{*}{ Response } & \multirow{2}{*}{\multicolumn{4}{|c|}{$\begin{array}{l}\text { Optimized value of input process } \\
\text { parameters }\end{array}$}} & \multirow{2}{*}{\multicolumn{4}{|c|}{$\begin{array}{l}\text { Modified value of input process } \\
\text { parameters }\end{array}$}} & \multirow{3}{*}{ Predicted value } & \multirow{3}{*}{ Experimental value } & \multirow{3}{*}{ Error \% } \\
\hline & & & & & & & & & & & \\
\hline & $A$ & $B$ & C & $D$ & $A$ & $B$ & $C$ & $D$ & & & \\
\hline JCB yield (\%) & 0.80 & 54.42 & 109.32 & 11.07 & 1.0 & 55 & 110 & 11 & 98.89 & 98.3 & 0.6 \\
\hline
\end{tabular}

TABLe 5: Fatty acid composition of JCB.

\begin{tabular}{|c|c|c|c|}
\hline Serial number & Fatty acid & Formula & \% Composition \\
\hline 1 & Palmitic acid & $\begin{array}{c}\mathrm{C}_{16} \mathrm{H}_{32} \mathrm{O}_{2} \\
\mathrm{CH}_{3}\left(\mathrm{CH}_{2}\right)_{14} \mathrm{COOH}\end{array}$ & 16.2 \\
\hline 2 & Stearic acid & $\begin{array}{c}\mathrm{C}_{18} \mathrm{H}_{36} \mathrm{O}_{2} \\
\mathrm{CH}_{3}\left(\mathrm{CH}_{2}\right)_{16} \mathrm{COOH}\end{array}$ & 8.2 \\
\hline 3 & Oleic acid & $\begin{array}{c}\mathrm{C}_{18} \mathrm{H}_{34} \mathrm{O}_{2} \\
\mathrm{CH}_{3}\left(\mathrm{CH}_{2}\right)_{7}-\mathrm{CH}=\mathrm{CH}-\left(\mathrm{CH}_{2}\right)_{7} \mathrm{COOH}\end{array}$ & 38.4 \\
\hline 4 & Linoleic acid & $\begin{array}{c}\mathrm{C}_{18} \mathrm{H}_{32} \mathrm{O}_{2} \\
\mathrm{CH}_{3}\left(\mathrm{CH}_{2}\right)_{4} \mathrm{CH}=\mathrm{CH}-\mathrm{CH}_{2}-\mathrm{CH}=\mathrm{CH}-\left(\mathrm{CH}_{2}\right)_{7} \mathrm{COOH}\end{array}$ & 36.8 \\
\hline 5 & Linolenic acid & $\begin{array}{c}\mathrm{C}_{18} \mathrm{H}_{30} \mathrm{O}_{2} \\
\mathrm{CH}_{3}\left(\mathrm{CH}_{2}\right)_{4} \mathrm{CH}=\mathrm{CH}-\mathrm{CH}_{2}-\mathrm{CH}=\mathrm{CH}-\mathrm{CH}_{2}-\mathrm{CH}=\mathrm{CH}-\left(\mathrm{CH}_{2}\right)_{4} \mathrm{COOH}\end{array}$ & 0.4 \\
\hline
\end{tabular}

of fitted model. The more the value of $R^{2}$ approaches unity, the better the model fits the experimental data. The value of the adjusted coefficient of determination $\left(R_{\mathrm{Adj}}^{2}: 0.923\right)$ is also high, thus indicating the significance of the model. The value of coefficient of variation (CV) is low $(2.09 \%)$, thereby indicating the reliability of the results of the fitted model [8].

$P$ values $<0.05$ indicate that the model terms are significant [10]. In this case, $A$ (catalyst concentration), $C$ (time), $D$ (ratio of methanol/oil), interaction effect of $A B$ (catalyst concentration with reaction temperture), $A C$ (catalyst concentration with reaction time), $B D$ (reaction temperature with methanol/oil ratio), $C D$ (time with ratio of methanol/oil), $B^{2}$ (quadratic effect of temparature), $C^{2}$ (quadratic effect of time) have significant effect on the JCB yield. The regression equation (3) for the determination of predicted values of output parameter (i.e., JCB in this study) is given as follows:

$$
\begin{aligned}
\operatorname{JCB}(\%)= & 343.90+34.43 A-8.34 B-0.46 C-15.19 D \\
& -0.93 A B-0.035 A C+0.58 A D \\
& +0.0023 B C+0.25 B D+0.04 C D-1.25 A^{2} \\
& +0.075 B^{2}+0.0006 C^{2}+0.0023 D^{2} .
\end{aligned}
$$

The graph between the predicted and actual JCB yield (\%) given in Figure 1 shows that the predicted values are quite close to the experimental values, thereby validating the reliability of the model developed for establishing a correlation between the process variables and the JCB yield.

\subsection{Effect of Process Parameters on JCB Yield. Figure 2} shows the effect of catalyst concentration $(\mathrm{NaOH})$, reaction temperature, reaction time, and molar ratio of methanol/oil on JCB yield. It can be seen from the figure that the JCB

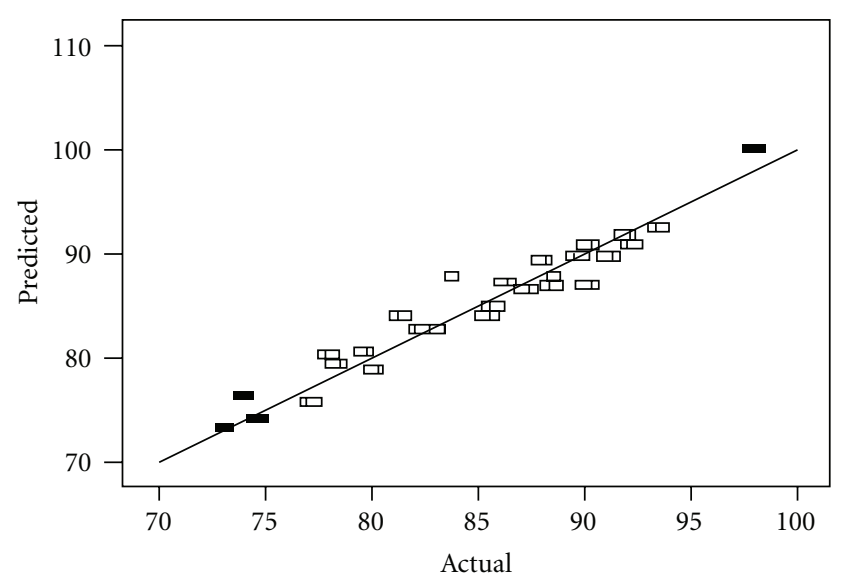

FIGURE 1: Predicted versus actual JCB (\%) yield values.

yield decreases significantly with an increase in catalyst concentration. This may be due to the fact that addition of excessive catalyst causes more triglyceride to react with the alkali catalyst leading to the formation of soap, which decreases the biodiesel yield [11]. JCB yield decreases with an increase in temperature till the middle point is reached, after that it increases. The increase in biodiesel yield at higher temperature is due to the fact that viscosity of oils decreases at high temperature and results in an increased reaction rate and shortened reaction time, thereby, increasing the biodiesel yield [11]. Reaction time has a positive effect on the JCB yield, as it increases with increase in time. This can be supported by the work of Freedman et al. [12] who found that the conversion rate of fatty acid esters increases with reaction time. At the beginning, the reaction is slow due to the mixing and dispersion of alcohol into the oil. After a while, the reaction proceeds very fast, thereby increasing the biodiesel yield. Yield of JCB is found to increase with the 
TABLe 6: Physicochemical properties of JCB.

\begin{tabular}{|c|c|c|c|c|c|c|c|}
\hline Serial number & Property (unit) & ASTM D6751 & IS 15607 & $\begin{array}{c}\text { JCB prepared } \\
\text { under } \\
\text { optimum } \\
\text { parameters }\end{array}$ & JCB [9] & ASTM D6751 limits & IS 15607 limits \\
\hline 1 & Viscosity (cSt; $\left.40^{\circ} \mathrm{C}\right)$ & ASTM D445 & IS 1448 & 4.9 & 4.38 & $1.9-6.0$ & $2.5-6.0$ \\
\hline 2 & Density $\left(\mathrm{g} / \mathrm{c} \cdot \mathrm{c}\right.$ at $\left.15^{\circ} \mathrm{C}\right)$ & ASTM D4052 & IS 1448 & 0.862 & - & - & $0.860-0.900$ \\
\hline 3 & Flash point $\left({ }^{\circ} \mathrm{C}\right)$ & ASTM D93 & IS 1448 & 174 & 172 & Minimum of 130 & - \\
\hline 4 & Water and sediment (Vol \%) & D2709 & D2709 & 0.05 & 0.05 & Maximum of 0.05 & Maximum of 0.05 \\
\hline 5 & Free glycerin (\% mass) & D6584 & D6584 & 0.01 & 0.01 & Maximum of 0.02 & D6584 \\
\hline 6 & Oxidative stability of JCB (h) & EN14112 & - & 3.3 & 3.27 & 3 & - \\
\hline 7 & Free glycerol & D6584 & D6584 & 0.015 & 0.01 & Maximum of 0.02 & Maximum of 0.02 \\
\hline 8 & Total glycerol & D6584 & D6584 & 0.14 & 0.12 & Maximum of 0.25 & Maximum of 0.25 \\
\hline 9 & Ester content $(\%)$ & - & EN 14103 & 98.3 & 98.5 & - & Minimum of 96.5 \\
\hline
\end{tabular}

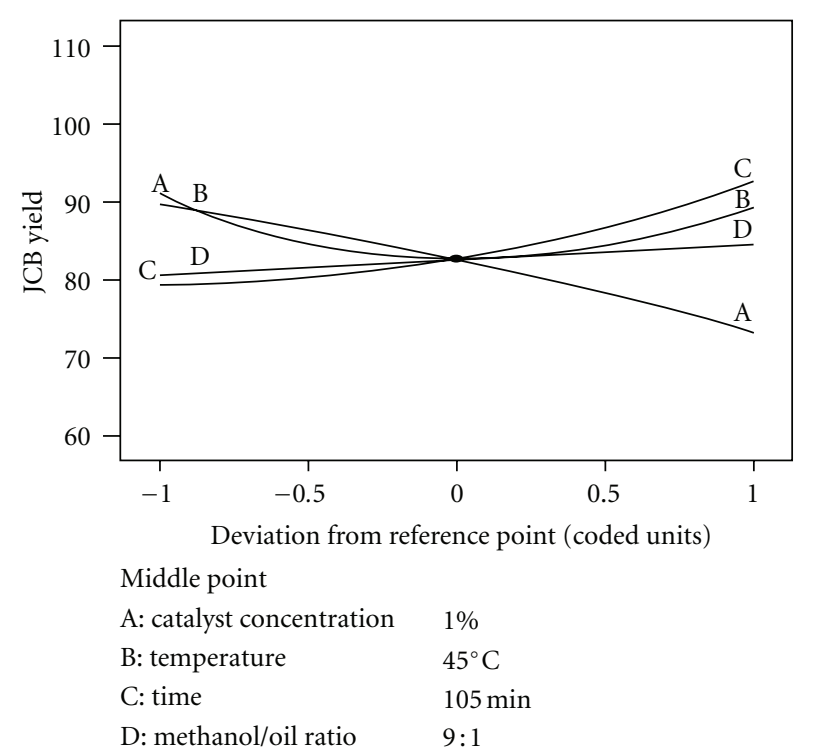

FIGURE 2: Effect of catalyst concentration, temperature, time, and methanol/oil ratio on JCB (\%) yield.

increase in methanol/oil ratio; since the transesterification reaction is reversible in nature, so excess alcohol is added to ensure the total conversion of triglycerides [11]. Thus, the yield of biodiesel increases with an increase in methanol quantity.

$3 \mathrm{D}$ response surfaces, which are the representation of the relationship between the responses and process parameters, are shown in Figures 3(a)-3(f). Figure 3(a) shows the influence of catalyst concentration $(\mathrm{NaOH})$ and temperature on the JCB yield. It can be seen that JCB yield increases with an an increase in reaction temperature at low amount of catalyst. Being an equilibrium reaction, the equilibrium constant is influenced by temperature; therefore, as the temperature increase, JCB yield also increases. However, JCB yield decreases at high temperature for high catalyst concentration. This may be due to the diffusion resistance between different phases of oil-methanol-catalyst at high amounts of catalyst. These results are similar to the findings of Chin et al. [4]. The influence of catalyst concentration and time on the JCB yield is shown in Figure 3(b) which indicates that the JCB yield increases with increase in reaction time at low catalyst concentration while it decreases at high catalyst concentration and high temperature and is supported by the work of Rashid et al. [8]. Figure 3(c) gives the effect of catalyst concentration and ratio of methanol/oil on the JCB yield. The contours do not have any significant effect on the JCB yield. Figure 3(d) establishes the interaction of temperature and reaction time on the JCB yield and shows that the interaction effect of reaction temperature and time has a favorable effect on increasing the JCB yield and is similar to the finding of Rashid et al. [8]. The effect of temperature and quantity of methanol given in Figure 3(e) indicates that the JCB yield increases at higher temperature and high methanol/oil ratio. This may be due to the fact that excess methanol can promote the transesterification reaction forward and increase the biodiesel yield. Figure 3(f) shows the influence of reaction time and quantity of methanol on the JCB yield. The biodiesel yield increases at higher time and high methanol/oil ratio because the conversion rate of triglycerides increases with time and excess methanol favors the complete conversion to biodiesel.

3.2. Optimization of Response Parameters. Optimization of individual responses was performed separately to achieve the desired maximization of JCB yield based on the developed mathematical model (i.e., (3)). The "Design Expert 8.0.6" software was used to optimize the response, and the value of the response (JCB yield) was set at maximum. The optimal value of input process parameters is given in Table 4 . An experiment was carried out at the optimal parametric settings for JCB yield to obtain the targeted value of response parameter. The table shows the predicted value of JCB yield derived from the regression equation as well as the experimental result obtained by the optimal setting of the parameters. Predicted response is found to be in good 


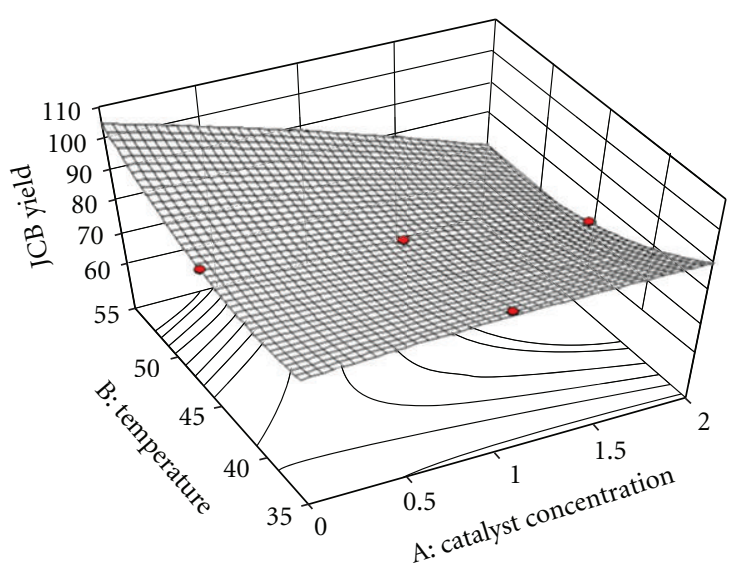

(a)

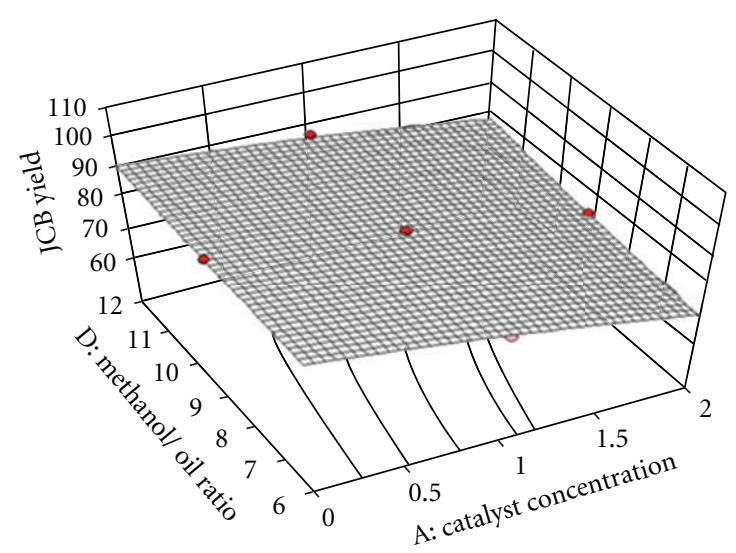

(c)

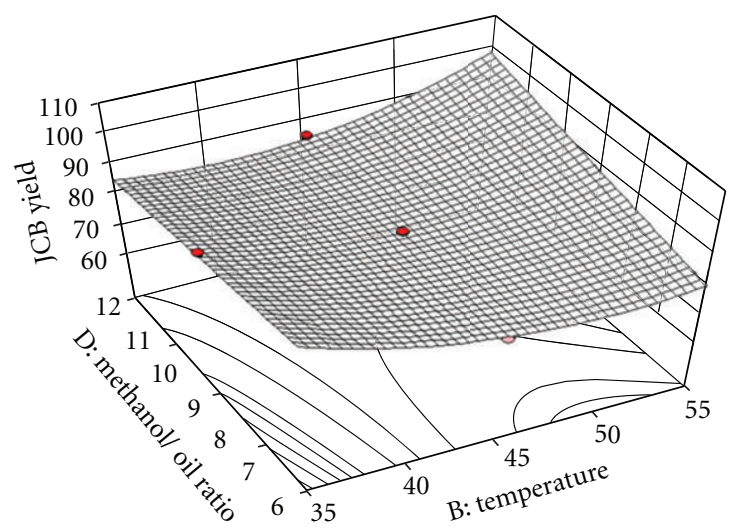

(e)

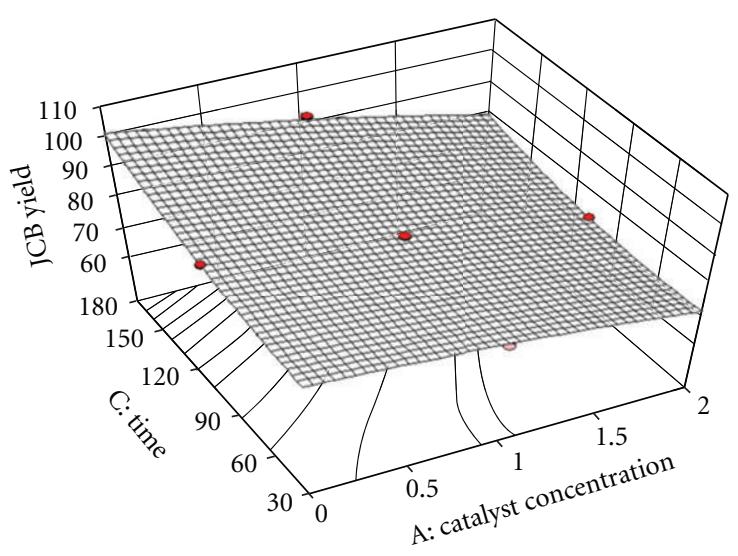

(b)

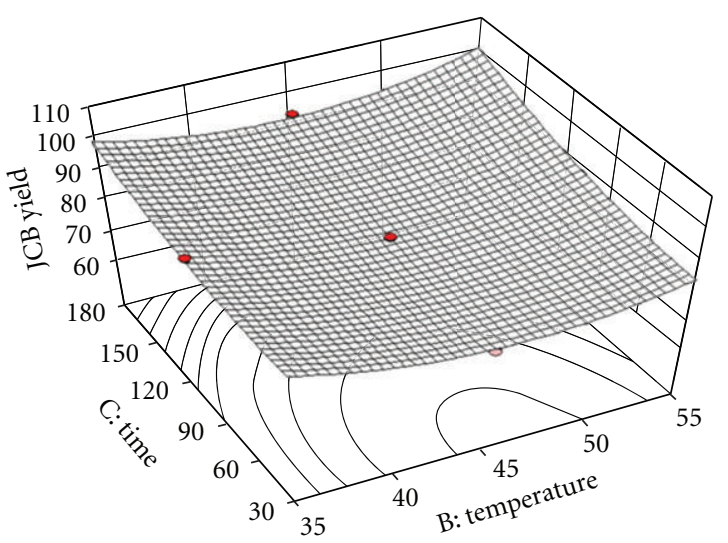

(d)

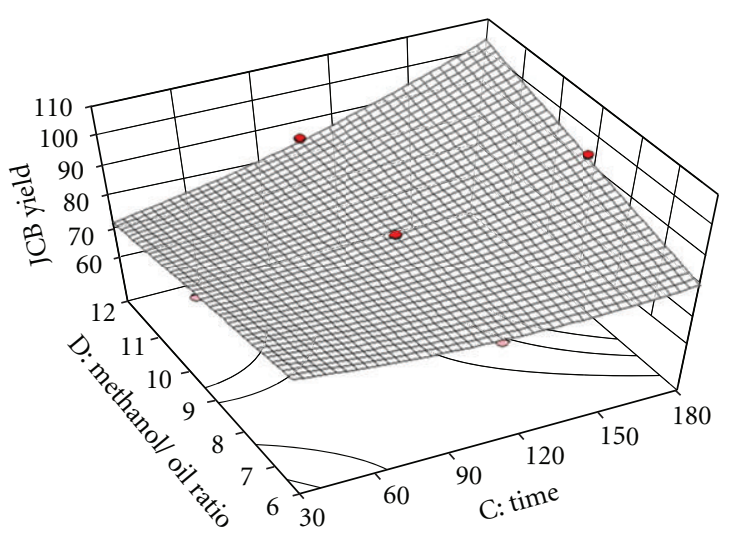

(f)

FIGURE 3: (a) Response surface of JCB: effect of catalyst concentration and temperature. (b) Response surface of JCB: effect of catalyst concentration and time. (c) Response surface of JCB: effect of catalyst concentration and methanol/oil ratio. (d) Response surface of JCB: Effect of temperature and time. (e) Response surface of JCB: effect of temperature and methanol/oil ratio. (f) Response surface of JCB: effect of time and methanol/oil ratio.

agreement with the experimental results with an error of $< \pm 1 \%$.

3.3. Analysis of JCB. The fatty acid (FA) composition of JCB prepared under the above optimum parameters and determined by gas chromatography (GC) is given in Table 5 which shows that JCB mainly contained oleic and linoleic acids. The FA composition is in good agreement with the composition reported by Jain and Sharma [9]. ${ }^{1} \mathrm{H}-\mathrm{NMR}$ spectra of JCB showed a singlet in $\delta 3.68 \mathrm{ppm}$ which is characteristic of methyl ester protons, and multiplet in $\delta 4.12-4.24$ and $\delta 5.30-5.34$ is attributed to oxymethylic hydrogen that is characteristic of triglycerides from Jatropha 
oil and is comparable with ${ }^{1} \mathrm{H}-\mathrm{NMR}$ spectral value of JCB reported in the literature [13], thereby indicating the purity of biodiesel prepared. From the NMR data, it was verified that Jatropha oil conversion into biodiesel was quite complete. The physio-chemical properties of JCB are reported in Table 6 . The properties of JCB are in good accord with ASTM and IS specifications.

\section{Conclusions}

The high FFAs (14.6\%) of JCO were reduced to $0.34 \%$ by its acid catalyzed pretreatment. Optimization of transesterification process of JCO was achieved by four-factorial CCD using RSM. A second-order model was obtained to predict the JCB yield as a function of process variables. The model can be successfully employed in the biodiesel industry to maximize the yield of methyl esters. On the basis of ANOVA, the catalyst concentration, reaction time, and methanol/oil molar ratio had a significant effect on JCB yield. A biodiesel yield of $98.3 \%$ was achieved with methanol/oil molar ratio $(11: 1)$ using $\mathrm{NaOH}$ as catalyst $(1 \% \mathrm{w} / \mathrm{w})$ in $110 \mathrm{~min}$ time at $55^{\circ} \mathrm{C}$ temperature. The prepared JCB conformed to the ASTM and IS standards specifications.

\section{Acknowledgments}

The authors acknowledge the financial support from the Ministry of Human Resource Development (MHRD), Government of India, in the form of a scholarship to carry out this work.

\section{References}

[1] S. Jain and M. P. Sharma, "Kinetics of acid base catalyzed transesterification of Jatropha curcas oil," Bioresource Technology, vol. 101, no. 20, pp. 7701-7706, 2010.

[2] K. Boonmee, S. Chuntranuluck, V. Punsuvon, and P. Silayoi, "Optimization of biodiesel production from jatropha oil (Jatropha curcas L.) using response surface methodology," Kasetsart Journal, vol. 44, no. 2, pp. 290-299, 2010.

[3] A. K. Tiwari, A. Kumar, and H. Raheman, "Biodiesel production from jatropha oil (Jatropha curcas) with high free fatty acids: an optimized process," Biomass and Bioenergy, vol. 31, no. 8, pp. 569-575, 2007.

[4] L. H. Chin, B. H. Hameed, and A. L. Ahmad, "Process optimization for biodiesel production from waste cooking palm oil (Elaeis guineensis) using response surface methodology," Energy and Fuels, vol. 23, no. 2, pp. 1040-1044, 2009.

[5] G. T. Jeong and D. H. Park, "Optimization of biodiesel production from castor oil using response surface methodology," Applied Biochemistry and Biotechnology, vol. 156, no. 1-3, pp. 431-441, 2009.

[6] G. T. Jeong, H. S. Yang, and D. H. Park, "Optimization of transesterification of animal fat ester using response surface methodology," Bioresource Technology, vol. 100, no. 1, pp. 2530, 2009.

[7] X. Yuan, J. Liu, G. Zeng, J. Shi, J. Tong, and G. Huang, "Optimization of conversion of waste rapeseed oil with high FFA to biodiesel using response surface methodology," Renewable Energy, vol. 33, no. 7, pp. 1678-1684, 2008.
[8] U. Rashid, F. Anwar, T. M. Ansari, M. Arif, and M. Ahmad, "Optimization of alkaline transesterification of rice bran oil for biodiesel production using response surface methodology," Journal of Chemical Technology and Biotechnology, vol. 84, no. 9, pp. 1364-1370, 2009.

[9] S. Jain and M. P. Sharma, "Correlation development for the effect of metal contaminants on the thermal stability of jatropha curcas biodiesel," Energy and Fuels, vol. 25, no. 3, pp. 1276-1283, 2011.

[10] P. Shandilya, P. K. Jain, and N. K. Jain, "Modeling and analysis of surface roughness in WEDC of SiCP/6061 Al MMC through response surface methodology," International Journal of Engineering Science \& Technology, vol. 3, no. 1, pp. 531-535, 2011.

[11] D. Y. C. Leung, X. Wu, and M. K. H. Leung, "A review on biodiesel production using catalyzed transesterification," Applied Energy, vol. 87, no. 4, pp. 1083-1095, 2010.

[12] B. Freedman, E. H. Pryde, and T. L. Mounts, "Variables affecting the yields of fatty esters from transesterified vegetable oils," Journal of the American Oil Chemists Society, vol. 61, no. 10, pp. 1638-1643, 1984.

[13] U. Rashid, F. Anwar, A. Jamil, and H. N. Bhatti, "Jatropha curcas seed oil as a viable source for biodiesel," Pakistan Journal of Botany, vol. 42, no. 1, pp. 575-582, 2010. 

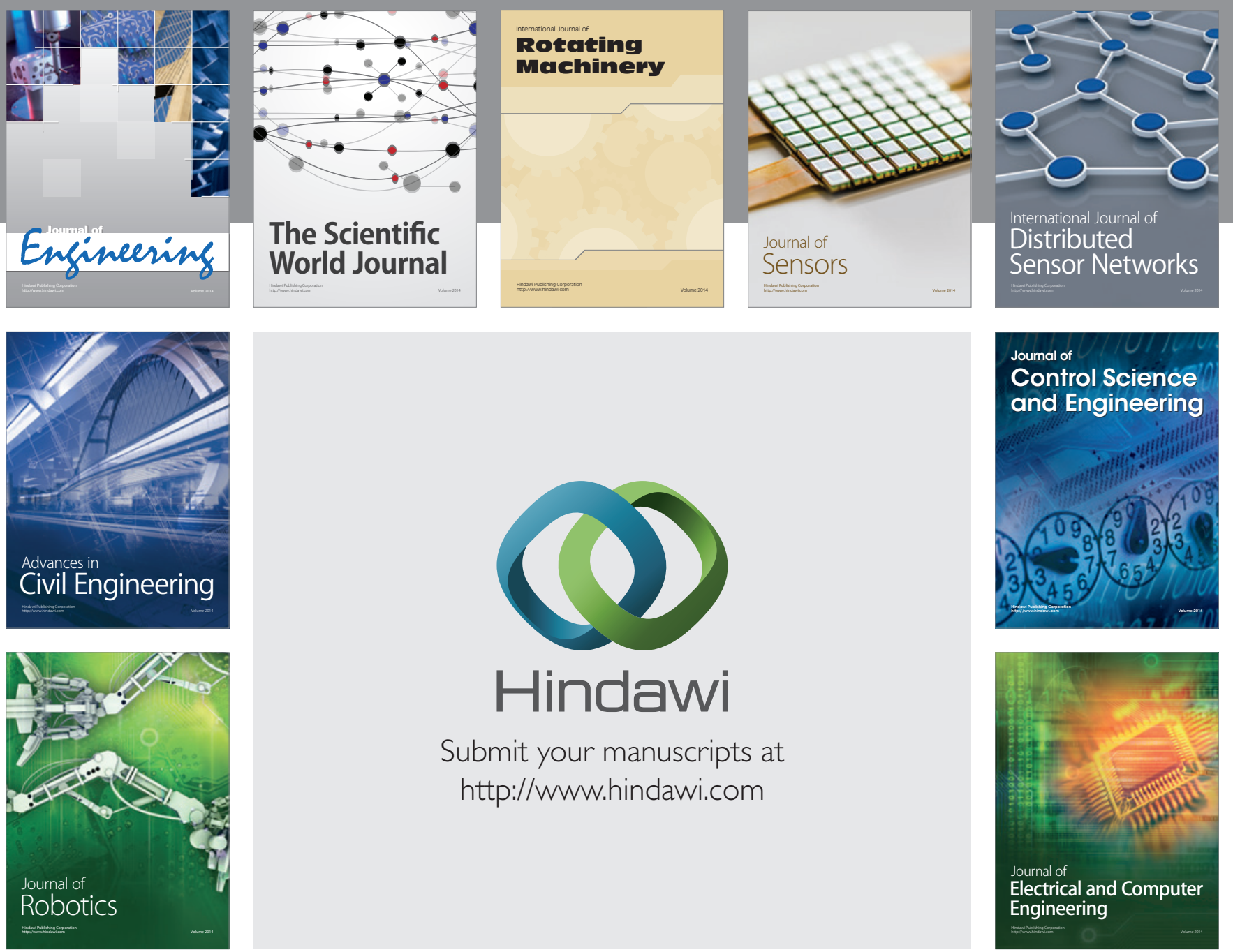

Submit your manuscripts at

http://www.hindawi.com
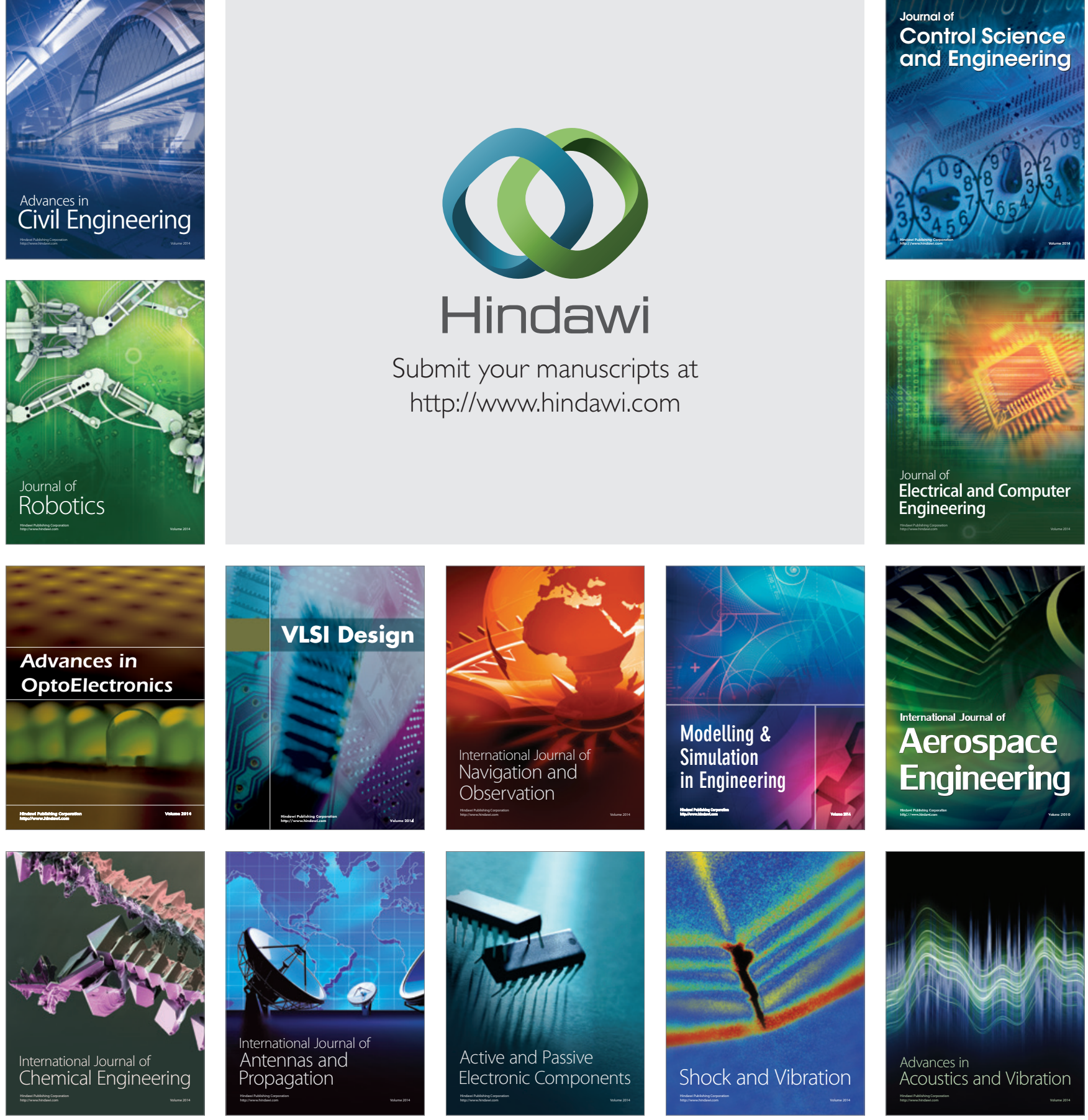